\title{
ESPECIAL \\ Ensaio fotográfico: A Mão e a Folha
}

\author{
Photo Essay: The Hand and the Leaf
}

Ensayo fotográfico: La mano y la Hoja

\section{Wéltima Teixeira Cunha'}

\section{APRESENTAÇÃo}

O ensaio fotográfico foi realizado com base na articulação das imagens impressas das charuteiras, no cotidiano laboral, com o poema, A Mão e a Folha. Este poema retrata o resultado conclusivo da dissertação de mestrado da autora, intitulada Acepção de Risco de Adoecimento em LER/DORT por Charuteiras, do Programa de Pós- Graduação Saúde, Ambiente e Trabalho, da Universidade Federal da Bahia. A pesquisa teve a finalidade de analisar as repercussões das LER/DORT na vida das charuteiras de uma fábrica, que fica localizada no município de São Gonçalo do Campos-BA, e teve como base as narrativas de cada uma delas. Estas mulheres têm suas vidas pressionadas, pautadas e reguladas por uma dupla jornada: a do trabalho produtivo e a do trabalho doméstico/reprodutivo. Essa realidade traz um dado revelador: no Brasil, as LER/DORT representam a maior causa de afastamentos entre os trabalhadores dos diversos ramos produtivos, pela previdência social, sendo que, de cada dez trabalhadores acometidos por essas afecções, oito são mulheres. Esse fato resulta da inserção da mulher em atividades que pouco demandam do seu intelecto e tudo exigem da delicadeza e destreza de suas mãos, em ambientes onde predominam a monotonia e a repetitividade. Conclui-se que o trabalho produtivo — estático, manual, repetitivo e monótono - e o doméstico/reprodutivo, com suas cargas somadas e potencializadas, são fatores determinantes do desencadeamento das LER/DORT nas charuteiras pesquisadas, que passam a jornada de trabalho manipulando e enrolando folhas do fumo para produzir os charutos.

\footnotetext{
1 Professora do Instituto Federal de Educação, Ciências e Tecnologia da Bahia (IFBA) - Campus de Vitória da Conquista - Bahia - E-mail: weltimateixeira@ifba.edu.br
} 


\section{A MÃO E A FOLHA}

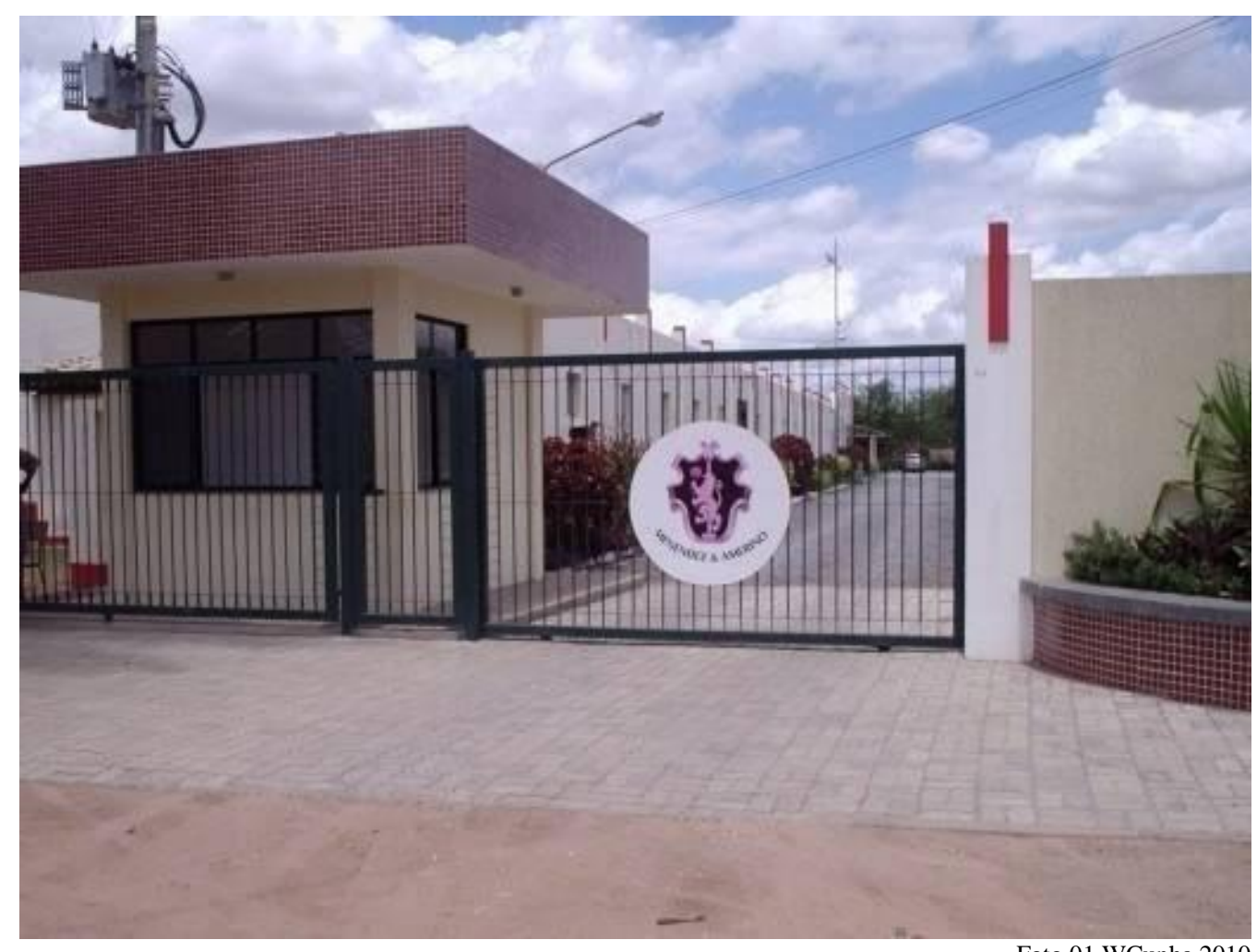

Foto 01 WCunha 2010
A folha, eu viro e enrolo, desde menina. Sou charuteira, trabalhadeira. 


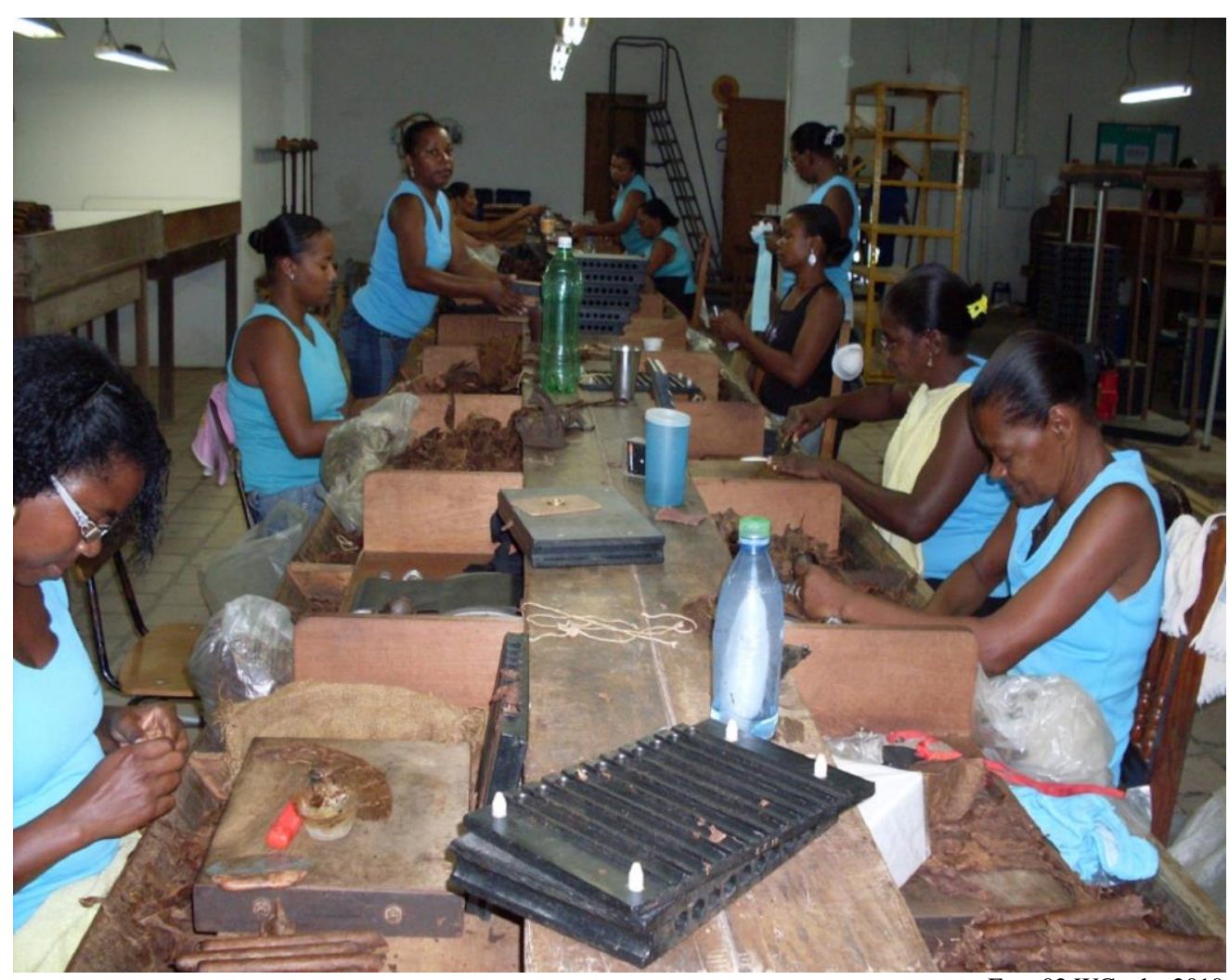

Foto 02 WCunha 2010

E como viro e enrolo a

folha. Desenrolo a

minha sina. No

trabalho, dói a mão. 


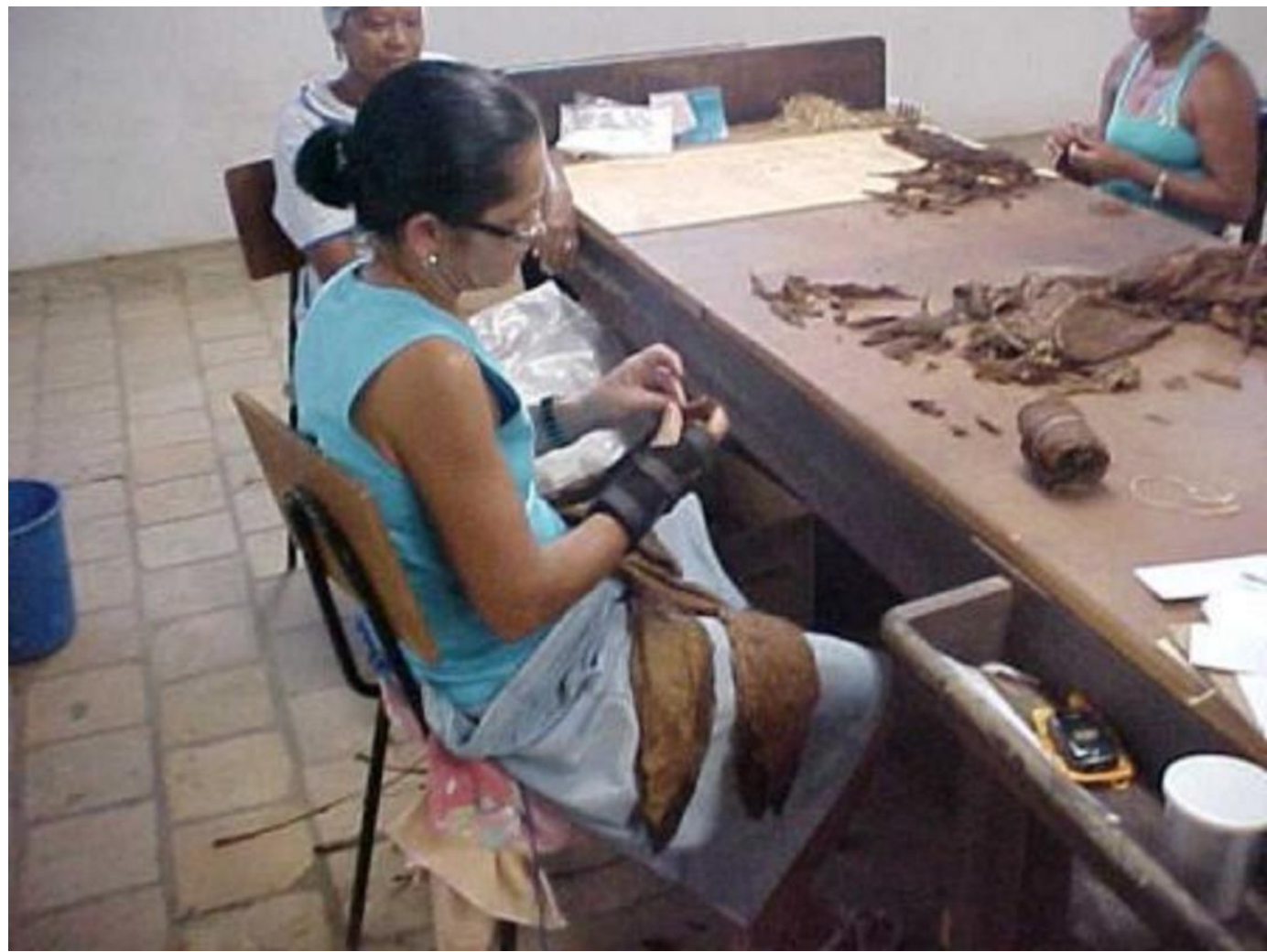

Foto 03 WCunha 2010

A mesma mão, em casa, lida

Com criança e marido

E tarefa de fogão, pia, tanque e varal.

Meu ofício não é mau 


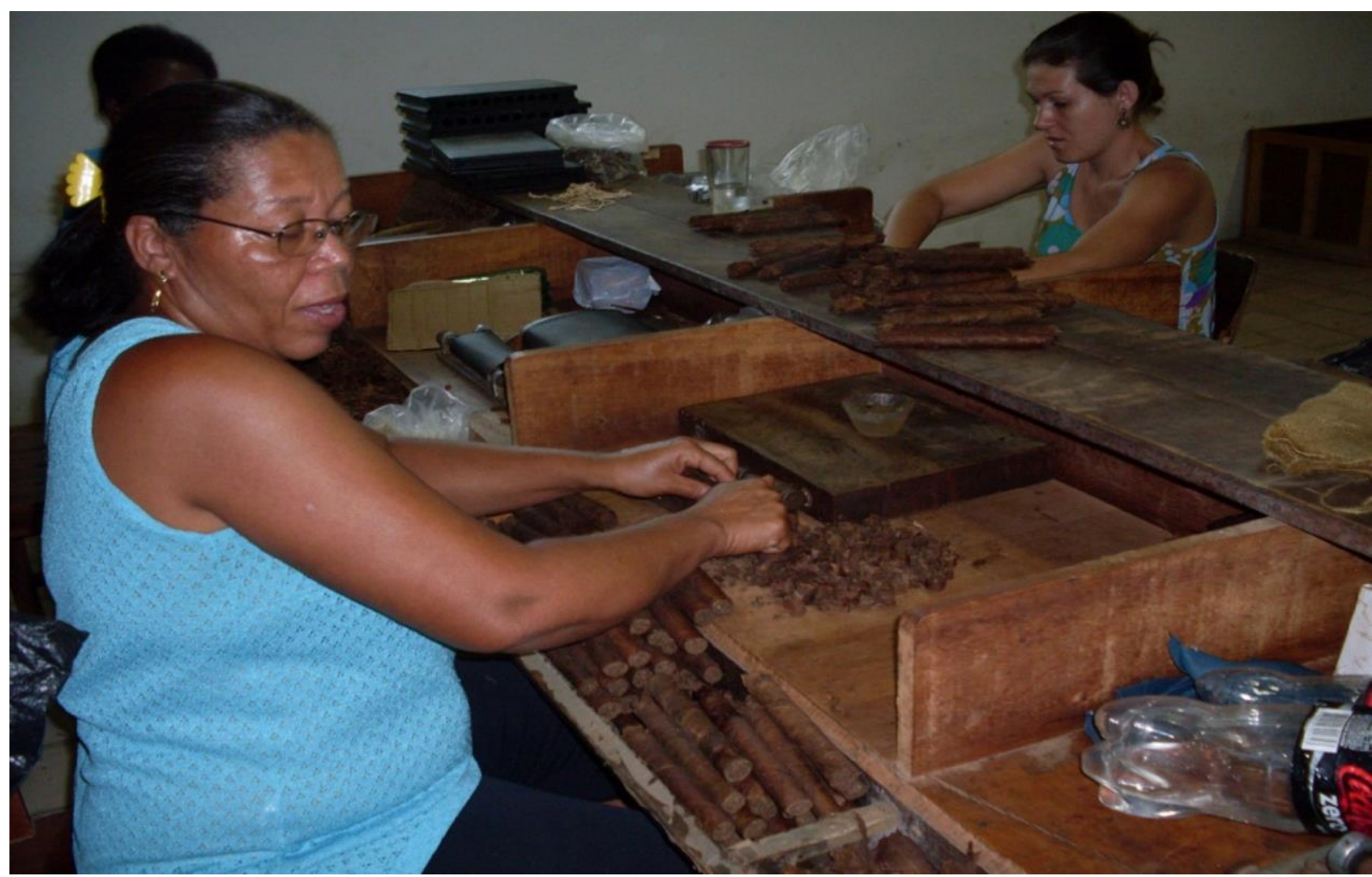

Foto 04 WCunha 2010

E comparo a vida que levo. Com

a folha que eu viro.

Mas se eu enrolo a folha.

Não dá pra enrolar o patrão. 


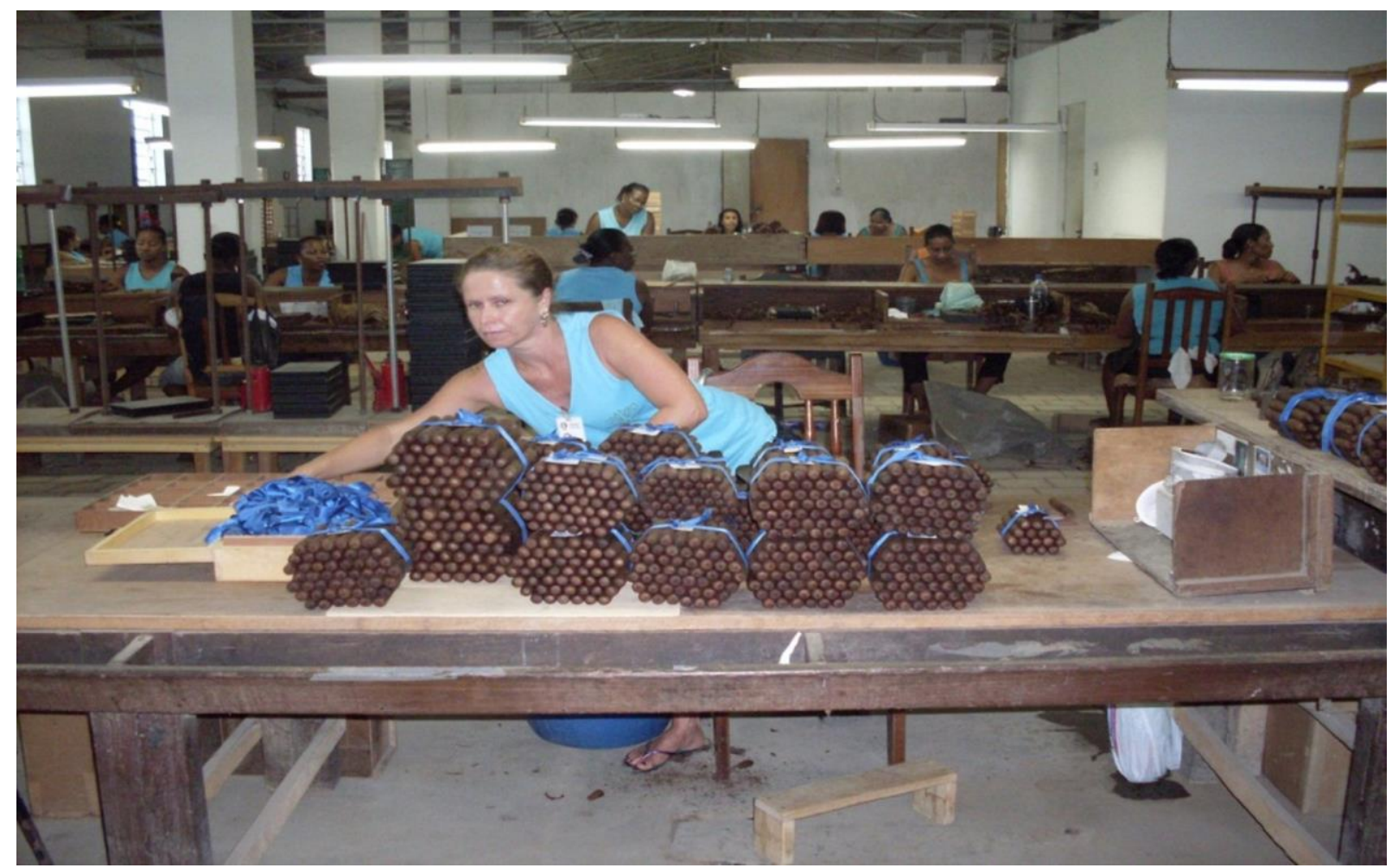

Foto 05 WCunha 2010

Se não cumprir produção

Sou como folha virada

E, aí, a mão que dói

É a mesma que fica na mão.

Laborare. Ano I, Número 1, Julho/2018, pp. 181-186. ISSN 0000-0000. http://trabalhodigno.org/laborare 